experiment with these or alternative methods of audit as an aid to training.

\section{Acknowledgements}

We would like to thank the members of the Newcastle Registrar Rotation who took part in the study, together with Mr Alan Warren and Janssen Ltd for provision of $\log$ books.

\section{References}

STEIN, S. (1986) Psychiatry Training in the USA. Talk to the Psychiatric Tutors Conference, York, September 1986.

WORKING PARTY FOR ReVIeW OF THE MRCPSYCH (1985) Report to the Court of Electors. (Royal College of Psychiatrists).

\title{
Postgraduate training course in the psychiatry of mental handicap
}

\author{
Dora KoHen, Senior Lecturer/Honorary Consultant in Psychiatry of Mental Handicap, \\ Charing Cross and Westminster Medical School, 24 St Dunstans Road, \\ London W6 8RP
}

Among other things, good medical practice demands continuation of training at every level of professional life. Post-membership psychiatrists who have started their senior registrar (SR) jobs may face a lack of formal training. In many subspecialities of psychiatry this has been extensively remedied by various training courses and programmes.

North West Thames Regional Health Authority (NWTRHA) has six SRs training in the psychiatry of mental handicap distributed to three large mental handicap hospitals. Part of my job as a senior lecturer at Charing Cross and Westminster Medical School has been to start a formal training course for SRs in the psychiatry of mental handicap in the region. Formal training had not taken place in this subspeciality previously although there had been several informal attempts in the region.

The first step was contacting the clinical tutors and the SRs to find out about their needs, wishes, plans and expectations of the course. Their responses clearly identified the great deal of enthusiasm and support which was to follow.

The detailed programme for the course was prepared much before the beginning of each term and needs and expectations of the group were taken into account; the final form was distributed to all consultants in the psychiatry of mental handicap at NWTRHA for comments and contributions.

\section{The course}

The course consisted of one session per week for 12 sessions per term. A total of 36 sessions in three terms have been held at Charing Cross and Westminster Medical School from September 1989 to July 1990. Course participants have been the SRs and other post-membership psychiatrists individually interested in the subjects. The sessions started with short announcements of congresses, conferences, forthcoming events, and news from different journals on subjects pertinent to mental handicap. It continued with a formal lecture or seminar on the scheduled subject lasting for $\mathbf{4 0}$ to $\mathbf{6 0}$ minutes which was followed by the journal club. The journal club consisted of recent reviews or original research papers on the same subject. The SRs were given the original papers a week in advance and each was expected to read all the papers and to prepare a presentation of one or two papers for 15-20 minutes. The sessions ended with a 30-minute discussion on the subject.

Informal research supervision has been included in the sessions on a monthly basis. The SRs summarised their work at whichever stage it happened to be. There was usually a lively discussion, ranging from the choice of subjects to the problems in the publication of the presented work. All participants were given the chance of presenting on at least one occasion. 


\section{The content}

Knowing the needs of the SRs, we started with basic sciences pertinent to our subspeciality (Kohen, 1990) and continued with behavioural sciences, various medical and psychiatric syndromes.

The aim was to have a comprehensive review of the several subjects in the psychiatry of mental handicap and to balance theoretical and basic subjects, together with more practical clinical matters of daily importance. In this 36-sessions course coverage of topics was as follows: basic sciences, 8; clinical syndromes, 8; psychiatric problems, 8; behavioural sciences, 5; services, 5; and socio-political aspects 2 sessions.

\section{Comments}

The course proved to be a successful and rewarding experience both for the trainees and the course organiser. The SRs' feedback communicated that the course had been a unique training experience for them. Attendance was satisfactory. Usually difficulties did not prevent attendance and for that we all have to thank the consultants for their goodwill and support. All presentations and discussions took place in an informal and friendly atmosphere.

As a course organiser, supervising 36 sessions weekly for three terms, screening several of the latest journals to prepare for the journal club every week in advance, photocopying and distributing the papers, preparing the announcements to keep all SRs abreast of novelties, and lecturing in many of the sessions may seem quite an impossible task. But the enthusiasm of the SRs, the improvement in the quality of their presentations and discussions, the favourable feedback from the clinical tutors, and the support of everybody involved in the region was sufficient motivation to continue.

After study leave approval and its formal announcement in April 1990, the course got a positive response from outside the region. Five SRs from neighbouring regions have now requested application forms and programmes for next year and three have expressed a wish to attend.

At present the main problem for the course is financial. Having outside speakers, secretarial help, and preparation of handouts, will all depend on financial support that may come from the districts.

Looking back at this first year, it is clear that both trainees and organiser have learnt a lot. Trainers have gathered information and discussion material that otherwise might not be accessible to them. They also practised and improved their presentation skills and gained confidence in teaching. As an organiser, I can say that the course gave a unique experience in devising and implementing a programme for higher training, modifying the content according to the needs of the trainees, and also learning about the organisation and management of postgraduate training. It has also proved that it is possible, and very rewarding, to devise a postgraduate training programme with limited means but with the trainees' enthusiasm.

At the beginning of this second year, the course needs to be improved in two areas. It will be of great benefit if this course, which already has informal research supervision, could include supervision in a more formal, periodic, and comprehensive basis. Also speakers from other disciplines who would enhance multidisciplinary discussions should be involved regularly.

Lastly, I would very much like to share my one year experience with colleagues interested in organising training schemes in psychiatry.

\section{Reference}

KOHEN, D. (1990) Importance of basic sciences to education in psychiatry (Correspondence). Psychiatric Bulletin, 14, 430. 